\title{
Seosnurmen apilapitoisuuden määritys NIRS-analysaattorilla kuivatusta näytteestä
}

\author{
Arja Nykänen ${ }^{1)}$, Outi Kurri ${ }^{2}$ ja Jukka Kemppainen ${ }^{3)}$ \\ 1) MTT, $51900 J u v a$, arja.nykanen@mtt.fi \\ ${ }^{2)}$ MTT, 31600 Jokioinen, outi.kurri@mtt.fi \\ ${ }^{3)}$ MTT, 88600 Sotkamo, jukka.kemppainen@mtt.fi
}

\section{Tiivistelmä}

Eri kasveja sisältävien seosnurmien viljelyssä ja varsinkin tutkimuksessa on tärkeää tietää eri kasvilajien osuus kasvustossa. Eri kasveilla on erilaiset ominaisuudet ja niiden osuutta kasvustoissa halutaan usein säätää. Nurmissa yleinen seos on apila-heinäseos. Tähän saakka apilan osuus on määritetty joko silmämääräisenä arviona koeruudulta tai käsin erottelemalla satonäytteestä. Nämä menetelmät ovat kuitenkin joko epätarkkoja ja subjektiivisia tai hyvin työläitä ja siis kalliita.

NIRS (Near Infrared reflectance Spectroscopy) on analysaattori, joka pystyy mittaamaan lähes mitä tahansa, kunhan sille saadaan kehitettyä tarpeeksi hyvä kalibrointi. NIRS mittaa näytteen pintaan absorboituneen ja näytteen pinnasta detektoreille heijastuneen lähi-infrapunavalon suhteellisen intensiteetin eri aallonpituuksilla. Analysaattorin etuna on $\mathrm{mm}$., että näyte ei tarvitse muuta esivalmistelua kuin kuivatuksen ja jauhamisen, näytettä ei käsitellä kemiallisilla aineilla, analyysi on nopea ja helppo. Ulkomailla analysaattoria on käytetty menestyksekkäästi seosnurminäytteiden palkokasvipitoisuuden määrittämiseen. Tämän tutkimuksen tavoitteena on kehittää myös Suomeen MTTlle toimiva kalibrointi seosnurminäytteen apilapitoisuuden määrittämiseen. Ensimmäinen kalibraatio on nyt valmis ja sitä verrataan nyt viiteen Saksassa tehtyyn kalibraatioon.

Kokeessa oli mukana 4 aiemmin raportoitua saksalaiseen aineistoon perustuvaa kalibraatiota, yksi suomalaiseen näytemateriaaliin perustuva saksassa tehty kalibraatio sekä nyt Suomessa tehty suomalaiseen materiaaliin perustuva kalibraatio. Kalibrointien näytemateriaali, kalibroinnin muodostaminen sekä NIRS-analysaattori olivat erilaisia, mutta kaikissa käytettiin kalibraatiosuoran validointiin PLS regressiota, jotta saatiin kehitettyä kalibraatiot, jotka perustuvat koko mitattuun valon spektriin. Näytemateriaaleina oli puna- ja valkoapilaa, sinimailasta ja erilaisia heiniä. Osassa kalibraatioita käytettiin vain puhtaita heinä- ja palkokasvinäytteitä, osassa oli vain seoksia ja osassa sekä puhtaita näytteitä että seoksia. Seokset oli joko tehty käsin puhtaista näytteistä sekoittamalla tai ns. luonnollisia näytteitä, joiden apilapitoisuus oli määritetty osanäytteestä. Kaikissa muissa paitsi Saksassa tehdyssä suomalaiseen materiaaliin perustuvassa kalibraatiossa oli näytteitä 150-850 kpl. Kalibraatiot validoitiin tunnettuun palkokasvipitoisuuteen perustuvilla näytteillä.

Kaikki tässä vertaillut kalibraatiot osoittautuivat käyttökelpoisiksi kalibraatioiksi. Hyvällä kalibraatiolla voidaan päästä $\pm 5 \%$ tarkkuuteen, mikä on erittäin hyvä tulos. Käsin lajittelussakin voi kasveja mennä vääriin fraktioihin. Kalibraatio on sitä parempi, mitä laajempi näytepohja ja validointisarja sillä on. Suomessa kehitettyä kalibraatiota kehitetään jatkossa tältä pohjalta.

Avainsanat: nurmi, apilapitoisuus, puna-apila, NIRS 


\section{Johdanto}

Seosnurmien, Suomessa tyypillisesti puna-apilan (Trifolium pratense) ja heinien seokset, viljelyssä on tärkeää tietää niiden apilapitoisuus, koska apilan määrällä on merkitystä sekä karjan ruokinnassa että esimerkiksi tilan typpitaseiden laskennassa. Nurmen apilapitoisuuden perusteella voi arvioida myös nurmen lannoitusvaikutusta seuraavalle kasville. Apilapitoisten nurmien tutkimuksessa nurminäytteen apilapitoisuuden tunteminen on ensisijaisen tärkeää. Ruuduilta kerättyjen näytteiden lajittelu käsin eri kasvifraktioihin on työlästä ja aikaa vievää eli siis myös kallista. Nopeaa ja luotettavaa menetelmää tarvitaan.

NIRS (Near Infrared Reflectance Spectroscopy) on lähi-infrapunaspektroskopiaan perustuva menetelmä, jonka tärkeimmät edut ovat määritysten nopeus, näytteiden esikäsittelyä ei tarvita, ei kemikaaleja, soveltuu prosessiolosuhteisiin (on line- mittaukset), monta parametria samalla mittauksella ja stabiilit laitteet. Infrapuna-spektroskopia otettiin ensimmäiseksi käyttöön viljan analysoinnissa jo noin 30 vuotta sitten. NIRS mittaa näytteen pintaan absorboituneen ja näytteen pinnasta detektoreille heijastuneen lähi-infrapunavalon suhteellisen intensiteetin eri aallonpituuksilla (yleensä 1100 - 2 $500 \mathrm{~nm}$ ). Absorboituneen valon \%-osuus vaihtelee aallonpituuden, näytteen kemiallisen ja fysikaalisen rakenteen mukaan. Tästä osuudesta laite laskee näytteen ainesosakoostumuksen. Sopivien kalibrointien jälkeen voidaan eri aineosat analysoida näytteestä samanaikaisesti.

Useissa tutkimuksissa on todettu, että NIRS -analysaattorilla pystytään määrittämään seosnurminäytteestä sen palkokasvipitoisuus (Petersen et al., 1987, Coleman et al., 1990, Wachendorf et al., 1999, ja Locher et al., 2005a, 2005b). Näissä tutkimuksissa käytettiin kussakin erilaisia kalibrointitapoja ja erilaisia kasveja.

Tässä esityksessä vertaillaan viittä erilaista NIRS-kalibraatiota kuivatun ja jauhetun seosnurminäytteen apilapitoisuuden määrittämiseksi. Suomalaisen kalibraation kehittäminen kuuluu MMM:n rahoittaman Luomututkimusohjelman 2003-2005 projektiin 'Puna-apila tehokkaasti luomumaidoksi'.

\section{Aineisto ja menetelmät}

\section{Näytemateriaali kalibraatioissa}

Syksyllä 2003 verrattiin erilaisia kalibrointeja nurminäytteiden apilapitoisuuden määrittämiseksi Münchenin teknillisessä yliopistossa ja Christian-Albrechts yliopistossa Kielissä. Kaikki kalibroinnit testattiin suomalaisesta näytemateriaalista tehdyillä 10 seosnäytteellä, joissa apila ja heinä oli sekoitettu käsin punnitsemalla tietyn apilapitoisuuden mukaisiksi seoksiksi kuivatuista ja jauhetuista puhtaista heinä- ja apilanäytteistä. Näytteet oli kerätty vuonna 2003 kahdeksalta eri peltolohkolta, jotka olivat joko tavanomaisesti tai luonnonmukaisesti viljeltyjä. Näytteet olivat joko ensimmäisen tai toisen niiton sadosta.

Kokeessa oli mukana 4 aiemmin raportoitua saksalaiseen aineistoon perustuvaa kalibraatiota (Wachendorf et al., 1999, Locher et al., 2005a, 2005b) (Taulukko1). Kalibrointien näytemateriaali, kalibroinnin muodostaminen sekä NIRS-analysaattori olivat erilaisia, mutta kaikissa käytettiin kalibraatiosuoran validointiin PLS regressiota, jotta saatiin kehitettyä kalibraatiot, jotka perustuivat koko mitattuun valon spektriin. Kalibraatiossa K oli materiaalina 282 luonnollista puna-apilaraiheinänäytettä, jotka oli niitetty viikon välein eri tavoin lannoitetuilta koeruuduilta yhtenä vuonna. Todellinen apilapitoisuus määritettiin vierekkäisestä osanäytteestä käsin lajittelemalla.. Locher et al (2005a, 2005b) kehittivät 3 erilaista kalibraatiota (M1-M3) käsin lajitelluista monikasviseoksista, joissa oli puna-apilaa, sinimailasta ja heiniä. Näytteet oli kerätty 1999-2002 useilta eri luomutilalta Baijerissa, Saksassa. Kalibraatiossa M1 oli 334 puhdasta palkokasvi- ja heinänäytettä yhdeltä tilalta. Kalibraatio M2 sisälsi edellisen materiaalin lisäksi samalta tilalta kerätyt ja käsin tehdyt 63 seosnäytettä. Tähän näyteaineistoon lisättiin vielä 120 puhdasta palkokasvi- ja heinänäytettä erilaisilta pelloilta kalibraation M3 muodostamiseksi.

Edellisten lisäksi tehtiin Münchenissä Suomesta kerätyistä näytteistä kalibraatio (F1), joka koostui 17 puhtaasta heinänäytteestä ja 17 puhtaasta puna-apilanäytteestä (Taulukko 1), jotka oli kerätty samoin kuin vertailuaineistona käytetty näytemateriaali.

Suomessa aloitettiin tänä vuonna oman kalibraation kehittäminen MTTn Kemian laboratorion NIRS-analysaattorilla. Kalibraation (F2) aineisto koostuu tällä hetkellä 74 heinänäytteestä, 54 puna- 
apilanäytteestä sekä käsin tehdyistä 28 seoksesta. Näytteet on kerätty 2003-2004 neljältä eri paikkakunnalta kahdesta niitosta. (Taulukko 1).

Taulukko 1. Vertailussa käytettyjen kalibraatioiden näytemateriaali.

\begin{tabular}{lll}
\hline Kalibraatio & Viite & Kalibraationäytteet \\
K & Wachendorf et al 1999 & 282 luonnollista puna-apila- ja heinäseosta, lannoituskokeelta \\
M1 & Locher et al 2005a & 334 heinä- ja palkokasvinäytettä yhdeltä tilalta \\
M2 & Locher et al 2005a & M1 + 63 käsin tehtyä seosta heinistä ja palkokasveista, yhdeltä tilalta \\
M3 & Locher et al 2005b & M2 +120 palkokasvi- ja heinänäytettä, kerätty erilaisilta pelloilta \\
F1 & & 17 heinä- ja 17 puna-apilanäytettä Suomesta \\
F2 & & 74 heinä- ja 54 puna-apilanäytettä ja 28 käsin tehtyä seosta Suomesta \\
\hline
\end{tabular}

\section{NIRS analysaattorit}

Kalibroinnin K analysaattori oli monokromaattori (FOSS, USA). Kalibraatiot M1-M3 ja F1 mitattiin ja validoitiin FT-NIRillä (Vector, BRUKER, Ettlingen, Saksa). Suomessa tehty kalibraatio F2 tehtiin InfraAnalyzer 500:1la (BRAN+LUEBBE GmbH, Saksa). Validointi tehtiin kaikisssa kalibraatioissa PLS regressiolla, joka laskettiin ohjelmistoilla ISI (Kiel), OPUS (Munich) ja Sesame 3.1 (Suomi).

\section{Tulokset ja tulosten tarkastelu}

Kaikki testatut kalibroinnit toimivat hyvin, vaikka kalibraatioiden alkuperä on hyvinkin erilainen. Taulukkoon 1 on koottu erilaisia virhetermejä kuvaamaan kalibrointien tarkkuutta. RMSEP (Root mean square error of prediction) ja SEP (Standard error of prediction) kuvaavat testinäytteiden määritysvirhettä, kun taas RMSECV (Root mean square error of cross-validation) kuvaa kalibraation ristiin validoinnin virhettä. Bias on ennustettujen ja referenssiominaisuusarvojen välillä oleva keskimääräinen ero. Kalibroinnin F1 tulos on myös hyvä, vaikka se perustuu erittäin pieneen näytemäärään. Tämä johtunee siitä, että testiseokset oli tehty kalibroinnissa käytetyistä näytteistä.

Taulukko 2. NIRS-kalibraatioiden vertailu seosnurminäytteiden apilapitoisuuden määrittämisessä. (RMSECV = Root mean square error of cross-validation, SEP =Standard error of prediction, $\mathbf{R M S E P}=$ Root mean square error of prediction)

\begin{tabular}{|c|c|c|c|c|c|}
\hline \multirow[t]{2}{*}{ Julkaistun kalibroinnin viite } & \multirow[t]{2}{*}{ nimi } & RMSECV & SEP & bias & RMSEP \\
\hline & & \multicolumn{4}{|c|}{ 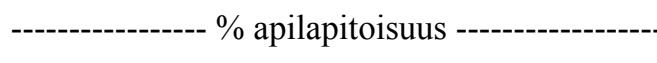 } \\
\hline Wachendorf et al. 1999 & $\mathrm{~K}$ & & 6.5 & 0.4 & 6.5 \\
\hline Locher et al. 2005a & M1 & 2.3 & 5.2 & -2.0 & 5.6 \\
\hline Locher et al. 2005a & M2 & 2.5 & 5.0 & 1.6 & 5.3 \\
\hline \multirow[t]{3}{*}{ Locher et al. 2005b } & M3 & 3.7 & 4.4 & -0.5 & 4.4 \\
\hline & $\mathrm{F} 1$ & 2.5 & 4.8 & -6.8 & 8.3 \\
\hline & $\mathrm{F} 2$ & & 6.8 & & 6.0 \\
\hline
\end{tabular}

Kalibrointien toimivuus validoitiin testinäytteillä, joita ei oltu käytetty itse kalibraatiossa. Kaikki kalibraatiot ennustivat näytteiden apilapitoisuuden erittäin hyvin. Korrelaatiokeroin oli 0,96 parhailla kalibraatioilla M3 ja F2 (Kuvat 1 ja 2), mikä on erittäin hyvä tulos. Kalibraatio toimii sitä paremmin, mitä laajempi sen muodostamisessa ja validoinnissa käytetty aineisto on. Eli näytteitä täytyy kerätä useamman vuoden ajan erilaisilta pelloilta erilaisina kasvuaikoina. Kalibroinneilla voidaan päästä $\pm 5 \%$ tarkkuuteen, jolloin muut virhelähteet näytteiden otossa ja käsittelyssä voivat aiheuttaa jopa suuremman virheen.

NIRS on siis hyvä menetelmä kuivatun ja jauhetun seosnurminäytteen apilapitoisuuden analysoimiseen. Koeruutujen niittokoneisiin on jo saatavissa lisälaitteena satosilppuri, joka ottaa näytteen sadosta tietyin määräajoin ja tämä näyte voidaan käsitellä kuten mikä tahansa kemiallinen näyte ilman käsin erottelua eri kasveihin. Erottelua tarvitaan ainoastaan siinä tapauksessa, kun apilasta ja heinästä halutaan tehdä kasvikohtaisia analyysejä. 


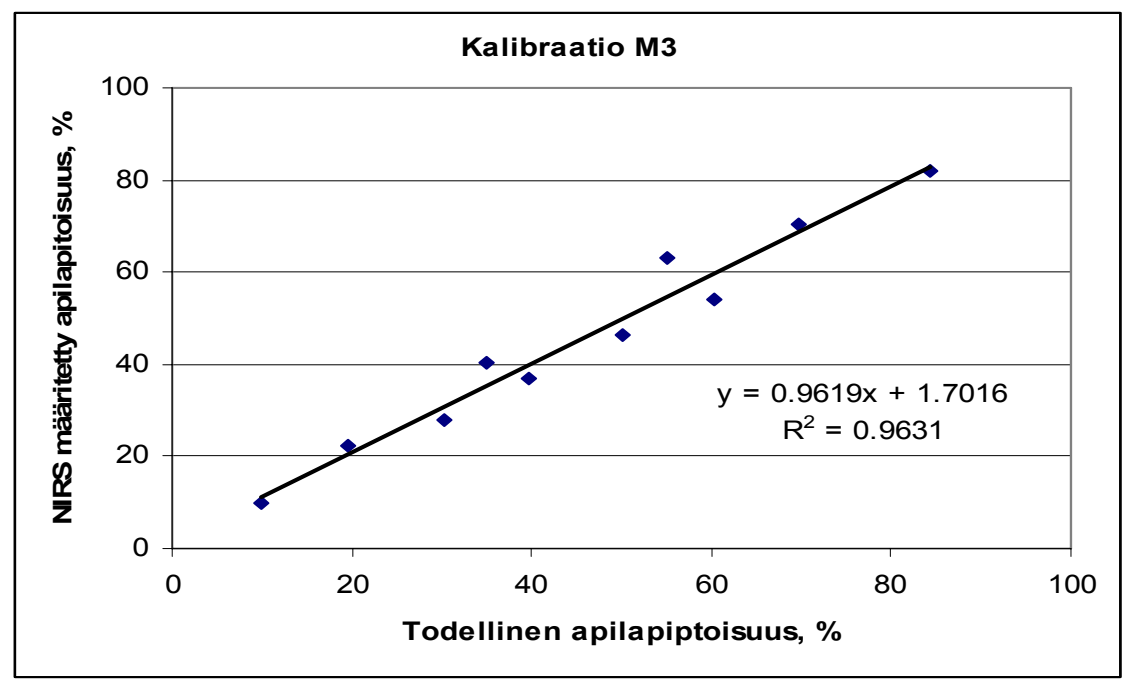

Kuva 1. NIRS -kalibraation M3 ennustamat arvot testinäytteiden apilapitoisuuksille.

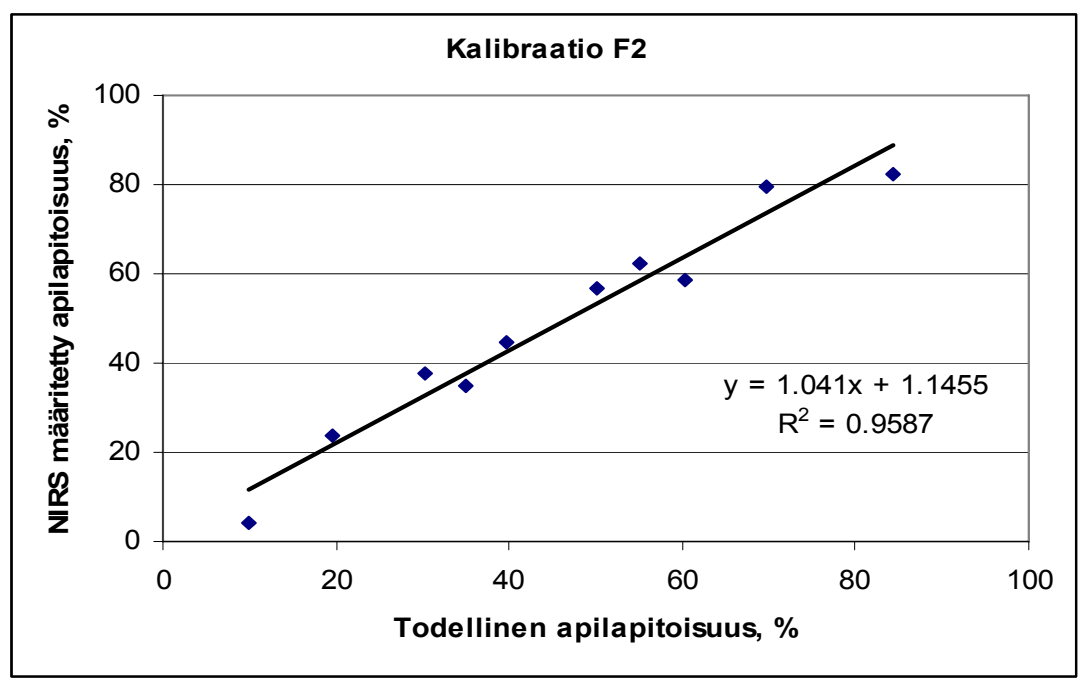

Kuva 2. NIRS -kalibraation F2 ennustamat arvot testinäytteiden apilapitoisuuksille.

\section{Johtopäätökset}

Kaikki tässä esitetyt kalibraatiot osoittautuivat hyviksi ennustamaan kuivatun ja jauhetun seosnurminäytteen apilapitoisuutta. Hyvä kalibraatio voi päästä jopa $\pm 5 \%$ tarkkuuteen, mikä on oikein hyvä tarkkuus, kun otetaan huomioon muut virhelähteet. Kalibraatio on sitä parempi, mitä laajempi näytepohja ja validointisarja sillä on. Suomessa kehitettyä kalibraatiota kehitetään jatkossa tältä pohjalta.

\section{Kirjallisuus}

Coleman, S.W., Christiansen, J.S. \& Shenk, J.S. 1990. Prediction of Botanical Composition using NIRS Calibrations Developed from Botanically Pure Samples. Crop Science. 30: 202-207.

Locher, F., H. Heuwinkel, R. Gutser \& U. Schmidhalter. 2005a. Development of Near Infrared Reflectance Spectroscopy Calibrations to Estimate Legume Content of Multispecies Legume-Grass Mixtures Agronomy Journal. 97: 11-17.

Locher, F., H. Heuwinkel, R. Gutser \& U. Schmidhalter. 2005b. The Legume Content in Multispecies Mixtures as Estimated with Near Infrared Reflectance Spectroscopy: Method Validation. Agronomy Journal. 97: $18-25$.

Petersen, J.C., Barton, II, F.E., Windham, \& Hoveland, C.S. 1987. Botanical composition definition of Tall fscue-White Clover mixtures by Near Infrared Reflectance Spectroscopy. Crop Science. 27: 1077-1080.

Wachendorf, M., Ingwersen, B. \& Taube, F. 1999. Prediction of the clover content of red clover- and white clover-grass mixtures by near-infrared reflectance spectroscopy. Grass and Forage Science. 54:87-90. 